\title{
Pelatihan Pembelajaran dan Penilaian Berbasis HOTS (Higher Order Thingking Skill) bagi guru SD
}

\author{
Effendi ${ }^{1}$ \& Wahid Gunarto ${ }^{2}$ \\ 1,2 Program Studi Pendidikan Fisika STKIP Nurul Huda \\ E-mail: 1 effendi@stkipnurulhuda.ac.id , ${ }^{2}$ wahidg@gmail.com
}

INFO ARTIKEL ABSTRAK

How to cite (APA):

Effendi, E., \& Gunarto, W. (2019). Pelatihan Pembelajaran dan Penilaian Berbasis HOTS (Higher Order Thingking Skill) bagi guru SD. Jurnal Indonesia

Mengabdi, 1(2), 40-43. Retrieved from

https://journal.stkipnurulhuda.ac.id/ index.php/JIMi/article/view/576

ISSN 2685-3035

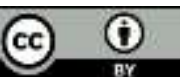

This work is licensed under a Creative Commons Attribution 4.0 International License

\begin{abstract}
Abstrak
Adanya kegiatan pengabdian bagi para guru ini dilandasi dengan semakin pesatnya perkembangan teknologi dan komunikasi sehingga menuntut pula perubahan dalam pola pembelajaran dan penialaian yang berkaitan dengan kemampuan berfikir. Pembelajaran yang melibatkan berfikir tingkat tinggi (HOTS) sangat diperlukan pada era revolusi industri 4.0 dan masa mendatang sebab ilmu pengetahuan yang terus berkembang, perubahan yang berlangsung tanpa henti dan persaingan hidup yang semakin ketat. Oleh karena itu pendidik harus berupaya bagaimana agar peserta didik mampu bersikap fleksibel dalam menyesuaikan diri dalam beradaptasi dengan perubahan-perubahan tersebut. Dalam pelaksanaannya kegiatan in menggunakan metode ceramah, diskusi dan Tanya jawab serta praktik. Materi yang disampaikan dalam kegiatannya yakni materi tentang pembelajaran dan penilaian HOTS. Setelah kegiatan dilaksanakan beberapa manfaat yang diperoleh yaitu: 1) secara umum peserta yang hadir sangat antusias terhadap materi yang sampaikan, 2) perserta merasa mendapatkan ilmu yang baru berkaitan dengan pembelajaran dan penilaian berbasis HOTS.

Kata kunci: Pembelajaran, Penilaian, HOTS
\end{abstract}

\begin{abstract}
The existence of the activities for teachers is based on the rapid development of technology and communication so as to also require changes in the pattern of learning and blowing related to the ability to think. Learning involving highlevel thinking (HOTS) is indispensable in the era of the 4.0 industrial Revolution and the future because of the evolving science, relentless changes and tougher life competition. Therefore educators should strive for how students can be flexible in adapting to the changes. In the implementation of this activity use lecture methods, discussions and FAQs and practice. The material presented in its activities is material about the HOTS learning and assessment. After the activities carried out some of the benefits that are obtained namely: 1) In general participants who attended very enthusiastic about the material that delivered, 2) and feel the new knowledge related to learning and assessment of HOTS-based.

Keywords: Learning, Evaluation, HOTS
\end{abstract}


Pelatihan Pembelajaran dan Penilaian Berbasis HOTS (Higher Order Thingking Skill) bagi guru SD

Jurnal Indonesia Mengabdi, 1(2), 2019

\section{PENDAHULUAN}

Keterampilan berfikir berhubungan dengan salah satu bagian dari fungsi otak. Semakin otak digunakan akan semakin mudah untuk menempatkan keahlian hinga berfikir kritis. Keahlian berfikir kritis sendiri melalui tahapan pengamatan, interprestasi, analisis, kesimpulan, evaluasi, penjelasan, dan metakognisi (Kuswana, 2013: 21). Dari beberapa tahapan proses berfikir HOTS dapat dijelaskan antara lain: tingkatan berfikir paling rendah yaitu keterampilan menghafal yang terdiri atas keterampilan yang hamper otomatis atau reflektif. Kemampuan berfikir dasar hanya menggunakan kemampuan terbatas pada hal-hal rutin dan bersifat mekanis. Kemampuan berfikir tingkat tinggi (HOTS) digunakan apabila seseorang menerima infromasi baru dan menyimpannya untuk kemudian digunakan atau disusun kembali untuk keperluan problem solving berdasarkan situasi yang ada.Berfikir kritis adalah berfikir yang memeriksa, menghubungkan, dan mengevaluasi semua aspek dari situasi atau masalah, termasuk di dalamnya mengumpulkan, mengorganisasi, mengingat, dan menganalisis informasi. Kemampuan berfikir kritis dan kreatif merupakan termasuk indicator kemampuan tingkat tinggi. Berfikir kreatif bukanlah sebuah proses yang sangat terorganisasi, sebagaimana berfikir kritis. Juga tidak seperti berfikir kritis yang mencoba untuk memperlembut emosi dengan cara memfokuskan diri pada proses logika sebagai bagian proses berfikir.

Menurut Johnson (2014:215) berfikir kreatif membutuhkan ketekunan, disiplin diri, dan perhatian penuh. Selain itu berfikir kreatif juga melibatkan aktivitas mental, seperti: mengajukan pertanyaan, mempertimbangkan informasi baru dan ide yang tidak lazim dengan fikiran terbuka, membangun keterkaitan, menerapkan imajinasi pada setiap situasi untuk menghasilkan hal baru, mendengarkan intuisi. Pada tataran proses pembelajaran terutama pada jenjang Sekolah Dasar (SD) sangat besar peran guru dalam menanamkan dan mengajarkan sikap berfikir siswa. Sejak dini siswa perlu dilatih dalam kemampuan berfikir, tidak hanya dalam kemampuan berfikir yang sekedar menghafal, tetapi juga pada aspek berfikir kritis. Selain dalam pembelajaran guru juga dituntut agar mampu memberikan proses penilaian yang sesuai dengan karakteristik siswa. Soal-soal yang digunakan dapat berupa pilihan ganda ataupun dalam bentuk uraian, yang terpenting adalah bagaimana seorang guru mampu membuat soal yang memenuhi komponen yang dapat dianalisis dan dievaluasi.

\section{METODE PELAKSANAAN}

Metode yang digunakan dalam kegiatan pengabdian kepada masyarakat terutama guru antara lain: 1Metode ceramah, metode diskusi dan praktik. Dalam menyampaikan tentang teori dan konsep pembelajaran serta penilaian berbasis HOTS menggunakan metode ceramah. Selanjutnya peserta langsung praktik membuat perangkat pembelajaran berbasis HOTS serta membuat soal-soal dengan pendekatan HOTS sesuai dengan lembar materi yang disediakan. Adapun ringkasan langkah-langkah kegiatan yang dilakukan antara lain:

1. Menyampaikan materi tentang konsep dasar pembelajaran HOTS

2. Menyampaikan materi tentang konsep dasar penialian HOTS

3. Praktik pembuatan dan revieuw hasil materi yang telah dilaksanakan 
Pelatihan Pembelajaran dan Penilaian Berbasis HOTS (Higher Order Thingking Skill) bagi guru SD Jurnal Indonesia Mengabdi, 1(2), 2019

\section{HASIL DAN PEMBAHASAN}

\section{Hasil}

Kegiatan yang pengabdian yang telah dilaksanakan ini tentu memiliki hasil yang cukup positif bagi peserta. Hasil yang telah dicapai dari kegiatan pelatihan pembelajaran dan penilaian berbasis HOTS ini secara umum adalah meningkatnya pengetahuan dan keterampilan guru berkaitan dengan istilah HOTS. Namun demikian karena terbatasnya waktu yang ada tim pengabdian belum mampu satu persatu menjawab semua pertanyaan dan saran yang diberikan oleh peserta. Adapun beberapa manfaat positif yang diperoleh yaitu:

1. Secara umum peserta yang hadir sangat antusias terhadap materi yang sampaikan,

2. Perserta merasa mendapatkan ilmu yang baru berkaitan dengan pembelajaran dan penilaian berbasis HOTS.

3. Peserta baru menyadari akan pentingnya penerapan pembelajaran dan penilaian berbasis HOTS

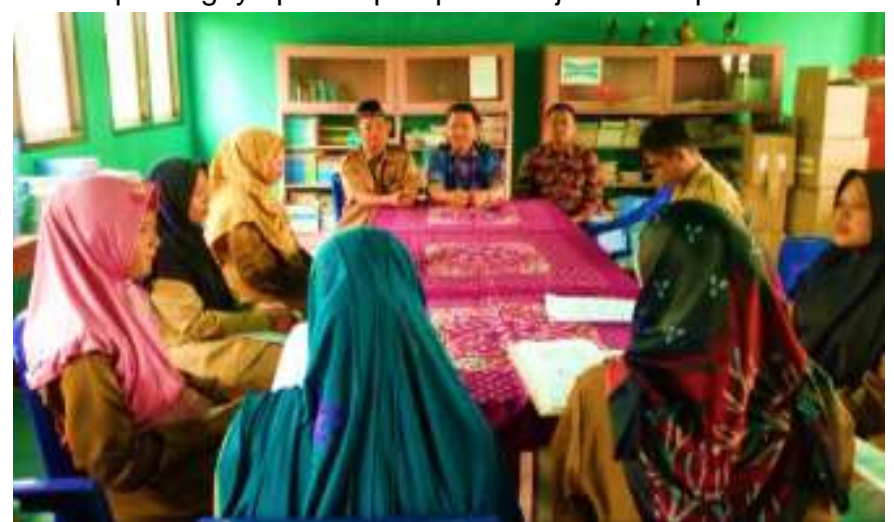

Gambar 1. Suasana Berdiskusi antara Peserta dengan TIM

\section{Pembahasan}

Tak ada manusia yang akan berhasil atau sukses dalam hidupnya hanya dengan mengandalkan kecerdasan intelektualnya saja. Untuk sukses dalam hidupnya manusia perlu beragam kecerdasan yang dapat dikembangkan melalui proses pendidikan dan pembelajaran. Dengan keterampilan tingkat tinggi (HOTS) manusia akan dapat mengasah diri dan menemukan bakat-bakat terpendam untuk menyelesaiakan persoalan yang dihadapi dalam hidupnya. Melalui keterampilan berfikir kritis, akan terbentuk SDM yang mampu menyelesaikan beragam masalah yang sangat kompleks baik yang dihadapi dirinya, keluarganya, masyarakat, bangsa dan Negara. Berbagai ide solusi kreativitas yang disampaikan oleh lulusan sekolah atau pendidikan yang memiliki kualifikasi dan kompetensi akan membantu menyelesaikan persoalan sosial, ekonomi, pendidikan, keamanan, kesehatan, kesejahteraan, kemajuan, pertahanan dan persatuan bangsa ini.

Penilaian hasil belajar oleh pendidik perlu dilakukan melalui mekanisme yang telah ditentukan dan bertujuan untuk memantau dan mengevaluasi proses, kemajuan belajar, dan perbaikan hasil belajar peserta didik secara berkesinambungan. Setelah penyampaian materi awal dilanjutkan dengan materi pengembangan soal-soal HOTS. Pembuatan soal diawali dari pembuatan indikator yang tepat. Penggunaan kata kerja operasional yang sesuai juga perlu diperhatikan. Sebab soal yang sulit belum tentu soal HOTS. Soal yang melibatkan proses bernalar, kreatif, memecahkan masalah, membuat keputusan, maka dengan demikian hal inilah yang sudah mencapai level HOTS.

\section{SIMPULAN}

Pelatihan pembelejaran dan penilaian berbasis HOTS perlu untuk diupayakan dan kembangkan seiring dengan perkembangan kemajuan zaman dan teknologi. Para guru memiliki beban yang berat dalam mencerdaskan anak anak bangsa. Oleh karena itu para guru sangat antusias dan responsive dalam kegiatan pelatihan. Sebab dengan demikian para guru merasa mendapatkan ilmu pengetahuan yang sangat bermanfaat bagi proses pembelajaran yang lebih baik. Dari kegiatan pengabdian ini disarankan agar ada tindaklanjut pada kegiatan-kegiatan selanjutnya sehingga pemahaman dan pengetahuan berkaitan dengan HOTS lebih optimal. 
Pelatihan Pembelajaran dan Penilaian Berbasis HOTS (Higher Order Thingking Skill) bagi guru SD Jurnal Indonesia Mengabdi, 1(2), 2019

\section{UCAPAN TERIMAKASIH}

Ucapan terima kasih ditujukan kepada Ketua STKIP Nurul Huda Sukaraja, Ketua LPPM STKIP Nurul Huda, yang berkenan untuk memfasilitasi kegiatan pengabdian kepada masyarakat ini. Serta kepada TIM pengabdian yang telah beruapaya sekuat tenaga demi kesuksesan kegiatan ini.

\section{DAFTAR PUSTAKA}

Aunurrohman. 2012. Belajar dan Pembelajaran. Bandung: Alfabeta.

Helmawati. 2019. Penilaian dan Pembelajaran Berbasis HOTS. Bandung: Remaja Rosdakarya Offset.

Helmawati. 2014. Pendidik Sebagai Model. Bandung: Remaja Rosdakarya Offset.

Mustaqim. 2008. Psikologi Pendidikan. Yogyakarta: Pustaka Pelajar.

Rose, Colin dan Malcolm J. Nicholl. 2014. Accelerated Learning: For the $21^{\text {st }}$ century "cara cepat belajar abad XXI". Bandung: Nuansa Cendekia.

Rusman. 2012. Model-model Pembelajaran Mengembangkan Profesionalisme Guru. Jakarta: Raja Grafindo Persada

Usman M Uzer. 2004. Menjadi Guru Profesional. Bandung: Remaja Rosdakarya Offset. 